\title{
SUSTENTABILIDADE EMPRESARIAL: \\ A QUESTÃo SOCIOAMBIENTAL SOB A ÓTICA DA ANÁLISE ECONÔMICA DO DIREITO
}

Corporate sustainability: the issue environmental the perspective of economic analysis of law

\begin{abstract}
André Luis Agner Machado Martins
Mestrado em Direito Econômico e Socioambiental pela PUCPR. Especialista em Direito Administrativo e Direito Processual Civil pelo Instituto de Direito Romeu Felipe Bacellar. Advogado. E-mail: andremartins@1mp.adv.br

\section{Nahima Peron Coelho Razuk}

Mestrado em Direito Econômico e Socioambiental pela PUCPR. Especialista em Direito Administrativo pelo Instituto de Direito Romeu Felipe Bacellar e em Direito Socioambiental pela PUCPR. Advogada sócia da banca Guilherme Gonçalves \& Sacha Reck Advogados Associados. E-mail:nahima@guilhermegoncalves.com.br
\end{abstract}

RECEBIDO EM: 01.10.12 Aprovado EM: 03.02.12

\section{Resumo}

$\mathrm{O}$ atual contexto econômico apresenta um dos grandes paradoxos contemporâneos. Diante da expectativa e necessidade de um crescimento econômico, aliado aos necessários investimentos alocados junto aos setores produtivos, a sociedade depara-se com um sistema jurídico de proteção socioambienta ${ }^{344}$. O desafio dos agentes econômicos, público ou privados, está

\footnotetext{
${ }^{344}$ Contextualizando a problemática proposta ao artigo, deve-se registrar que "mediante e o cresci-
} 
na promoção de suas atividades empresariais e estabelecimento de um mercado preferencialmente concorrencial, o qual, simultaneamente deverá enfrentar as novas demandas socioambientais. O presente artigo pretende compreender este aparente conflito, verificar seus efeitos e a possibilidade de enfrentá-lo através da chamada Análise Econômica do Direito. Trata-se de método que encontra raízes na ciência econômica como uma resposta à abstração e subjetividade verificada nas correntes teóricas jusnaturalistas e juspositivistas, as quais nem sempre consideraram o elemento da eficácia quando da compreensão do universo jurídico. Este enfrentamento demonstrará que o viés puro econômico deverá perceber e recepcionar a chamada demanda socioambiental moderna, tradicionalmente registrada no cenário empresarial como uma externalidade ocasionadora de aumento dos custos de transação, capaz de afastar parte dos agentes econômicos, os quais tendem a maximizar seus lucros.

Palavras-chave: Crescimento econômico. Socionmbiental. Análise ECONÔMICA DO DIREITO.

\section{Abstract}

The current economic environment presents a contemporary of the great paradoxes. Given the expectation and need for economic growth, combined with the necessary investment allocated to productive sectors, the company faces a legal system of environmental protection. The challenge of economic agents, public or private, is promoting its business activities and establishing a competitive market preferably, which simultaneously must meet new environmental demands. This article seeks to understand this apparent conflict, evaluate its effects and the ability to face it by calling Economic Analysis of Law. This is the method that is rooted in economics as a response to abstraction and subjectivity found in current theoretical jusnaturalistas and juspositivistas, which is not always considered effective when the element of understanding the legal universe. This will demonstrate that the bias confronting pure economic sense and should welcome the call demand modern environmental traditionally

mento econômico, aumentam-se também os meios para a proteção ambiental (novas tecnologias, maior conhecimento científico etc.). Simultaneamente, tornam-se cada vez maiores as exigências para a proteção do meio ambiente, com isto, aumentam também os gastos necessários para esta atividade. O que não significa necessariamente uma melhora do ambiente, mas somente uma manutenção do status quo do meio ambiente. Explico: aquecendo-se a atividade industrial, aumenta-se a pressão sobre o ambiente em termos de apropriação de recursos ou da produção de dejetos industriais, tornando maior o aparato de limpeza exigido para que o ambiente não entre em degeneração na razão direta do aumento de produção. (DERANI, C. Direito ambiental econômico. 3. ed. São Paulo: Saraiva, 2008. p. 87). 
recorded in business scenario as an externality that increases transaction costs, able to fend off the part of economic agents, which tend to maximize their profits.

Keywords: Economic Growth. Socio-environmental. Economic AnALYSIS OF LAW.

SumáRIO: Introdução. 1. Do jusnaturalismo à análise econômica do direito. 2. Elementos da análise econômica do direito. 3. A atividade econômica empresarial e a questão sociambiental. 4. A análise econômica da questão socioambiental. Conclusão. Referências.

\section{INTRODUÇão}

São diversos os estudos e artigos que buscam na Análise Econômica do Direito a resposta para as diversas situações jurídicas modernas. Trata-se de um método contemporâneo da Teoria do Direto o qual pretende fornecer subsídios ou respostas mais eficientes às demandas jurídicas e que possui forte vinculo com a questão econômica (e monetária).

Esta natureza de aproximação com a ciência econômica confere uma série de dificuldades sobre sua aplicabilidade quando diante de questões não puramente econômicas. Destas situações que não refletem caráter econômico puro, destacamse as demandas socioambientais modernas, que possuem natureza - a priori pautada pela indisponibilidade, ausência de cunho material ou mensurável.

Surge a aparente colisão de valores de ordem econômica e valores socioambientais. Neste sentido, Stigler ${ }^{345}$ pondera sobre a dificuldade de comunicação entre estes valores em razão da sua própria essência, ou seja, "é, pois, profunda a diferença de uma disciplina que procura explicar a vida econômica (e, de fato, toda a ação racional) e outra que pretende alcançar a justiça como elemento regulador de todos os aspectos da conduta humana" ${ }^{\text {346. }}$. A própria conciliação entre Direito e Economia, em razão de possuírem metodologias muito diversas, acaba por registrar uma das primeiras barreiras a ser superada ${ }^{347}$.

\footnotetext{
${ }^{345}$ STIGLER. Georde. Law or Economics? The Journal of Law and Economics, vol. 35, n. 2, out. 1992. pp. 462-463.

${ }^{346}$ PINHEIRO, Armando Castelar; SADDI, Jairo. Direito, Economia e Mercados. Rio de Janeiro: Elsevier, 2005. p. 4.

${ }^{347}$ SALAMA discorre que o Direito é ciência exclusivamente verbal, marcadamente hermenêuti-
} 
Mas será que a Análise Econômica do Direito possui realmente esta limitação? Estaria hábil a responder apenas e tão somente questões meramente de conteúdo econômico? Não estaria apto a enfrentar contemporâneo dilema entre o crescimento econômico e as demandas socioambientais?

$\mathrm{O}$ assunto que trata desta harmonização entre o crescimento e os aspectos socioambientais é pauta das grandes discussões, sendo citada sob a designação de desenvolvimento sustentável. Ou seja, a atuação dos agentes econômicos de forma a respeitar o contexto social e ambiental, permitindo a sua perpetuidade ${ }^{348}$. Tal condição encontra substrato no próprio ordenamento jurídico brasileiro, uma vez que da leitura sistemática dos preceitos propostos pela Constituição Federal, nos deparamos que a atividade econômica está inserida num conjunto que demanda a compatibilização com outros valores sociais, culturais ou ambientais.

Percebe-se, desta forma, um enorme desafio proposto para aos agentes econômicos, qual seja: desenvolver suas atividades e atuar num cenário econômico em busca da maximização de seus resultados, entretanto, através de uma gestão socioambientalmente comprometida (internalização da sustentabilidade).

\section{Do JUSNATURAlismo À ANÁLISE ECONÔMICA Do DIREITO}

O desenvolvimento da chamada Análise Econômica do Direito encontra espaço dentro da Teoria do Direito na condição de um contraponto crítico às demais correntes teóricas até então verificadas. Para melhor compreender sua

co, aspira à justiça e desenvolve sua crítica pela legalidade. Já a Economia é também matemática, marcadamente empírica, aspira ser científica e desenvolve sua crítica pelo custo (SALAMA, Bruno M. O que é Direito e Economia. In: TIMM, Luciano. Direito e Economia. Porto Alegre: Livraria do Advogado, 2008. p. 49).

348 Sobre este aprovisionamento para as gerações futuras, importante esclarecer que "não procedem os argumentos de que proteção aos recursos ambientais implica diminuição do crescimento econômico, como também são questionáveis os argumentos opostos de que só o crescimento econômico pode garantir proteção ambiental. Um crescimento negativo pode consistir numa diminuição da preocupação tecnológica para minimizar efeitos danosos dos dejetos finais da produção. Se a paralização do crescimento econômico dificulta um tratamento com a última palavra em técnica de limpeza ambiental (tratamento dos outputs indesejáveis), o aquecimento da produção econômica eleva necessariamente a quantidade de recursos a serem apropriados (input para o crescimento da produção).

De qualquer forma, o problema do esgotamento dos recursos naturais não é diretamente proporcional ao aumento ou diminuição do crescimento econômico. A velocidade da destruição dos recursos naturais

está diretamente comprometida com a forma em que se dá a sua apropriação pela sociedade. A quantidade de transformação de matéria e energia não depende do crescimento econômico, mas das características daatividade econômica (DERANI, Op. Cit., p. 88). 
concepção, fundamental apresentar, ainda que de modo extremamente sumário, algumas destas teorias as quais buscaram trabalhar com a questão da aplicação de normas jurídicas.

Para evolução e consagração das finalidades deste artigo, pertinente o conceito de estrutura do Direito proposto por Reale, para quem: "a estrutura do Direito é tridimensional, visto como um elemento normativo, que disciplina os comportamentos individuais e coletivos, pressupõe sempre uma dada situação de fato, referida a valores determinados ${ }^{349}$ ".

Esta estrutura tridimensional refletiria as seguintes categorias fundamentais: justiça (relacionada ao valor), validade (relacionada à norma) e eficácia (relacionada à sua aplicação fática). Daí, segundo Bobbio, "frente a qualquer norma jurídica podemos colocar uma tríplice ordem de problemas: 1) se é justa ou injusta; 2) se é válida ou inválida; 3) se é eficaz ou ineficaz ${ }^{350 " . ~}$

Desta estrutura tridimensional do Direito (justiça, validade e eficácia) partem as teorias que serão apresentadas. Dela, inclusive, será possível compreender a necessidade e pertinência da Análise Econômica do Direito.

A primeira Teoria do Direito a ser tomada como referência é a denominada por Direito Natural ${ }^{351}$. Sua compreensão reside na primazia da justiça sobre a validade no cerne da discussão do fenômeno jurídico, desta forma, concebe a existência de um direito anterior a toda lei positiva humana ${ }^{352}$. Sendo anterior ao direito positivado, sobre ele deverá se sobrepor em caso de contradição. Tal pressuposto natural de justiça deveria "preferir às leis positivas que lhes forem contrárias; [de modo que] o direito natural deve sempre prevalecer sobre o direito positivo" 353 .

Daí que, à luz do Direito Natural, a validade de uma determinada norma jurídica estaria vinculada ao preenchimento de requisitos formais e a coexistência da justiça e da moral. É desta concepção que decorre sua crítica. Parece fato que os conceitos de justiça e moral estão contemplados pela abstração e subjetivismo, os quais variam territorialmente e temporalmente, daí restaria flexibilizado o próprio pressuposto do Direito Natural, o qual poderia não trazer estabilidade às expectativas sociais.

A contrapartida ao Direito Natural foi a redução deste caráter subjetivo de justiça e validade. Surge, no século XIX, o denominado Positivismo Jurídico, o qual é marcado pela inversão destes elementos, ou seja, a validade (norma)

\footnotetext{
${ }^{349}$ REALE, Miguel. Filosofia do Direito. São Paulo: Saraiva, 2010. p. 511.

${ }^{350}$ BOBBIO, Norberto. Teoria da norma jurídica. Bauru, SP: Edipro, 2008. pp. 45-46

${ }^{351}$ Prevaleceu "desde o seu alvorecer até princípios do Século XIX" (RADBRUCH, Gustav. Filosofia do Direito. Coimbra: Coimbra Editora, 1997. p. 61),

${ }^{352}$ GUIMARÃES, José de Miranda. Direito Natural: visão metafísica e antropológica. Rio de Janeiro: Forense Universitária, 1991. p. 211.

${ }^{353}$ RADBRUCH, Gustav. Filosofia do Direito. Coimbra: Coimbra Editora, 1997. p. 62.
} 
passa a ocupar o centro da Teoria do Direito. Tal como as demais correntes da Teoria do Direito, o Positivismo encontra pluralidade de entendimentos com relação às suas características, mas, ainda sim, é possível registrar aquelas mais latentes, tais como ${ }^{354}$ : (i) a primazia do formalismo, (ii) a adoção de uma perspectiva normativista a qual considera a legislação como fonte principal do direito, reduzindo ao mínimo a relevância do costume, (iii) quanto à completude do ordenamento jurídico, considera-o completo, coerente, sem contradições ou lacunas, (iv) tem seu método marcado pela limitação da atividade do jurista à pura interpretação declarativa ou mecânica da norma, excluindo a função criativa do juiz e (v) prescreve a obediência estrita, ou até mesmo absoluta à lei.

Tal como a corrente naturalista, o chamado Positivismo Jurídico, especialmente após a segunda metade do Século XX, passou a ser alvo de críticas, em especial focadas nos seus pressupostos fundamentais. As críticas retratavam a dificuldade destas correntes em enfrentar ou propor uma explicação adequada do Direito como um fenômeno concomitantemente valorativo (aspecto justiça) e normativo (aspecto validade).

Desta forma, enquanto o Direito Natural "reduz a validade à justiça", o Positivismo Jurídico "reduz a justiça à validade" "355. É possível compreender que ambas as correntes teóricas ofereceram à chamada eficácia normativa um papel secundário na estrutura do Direito, a qual estava polarizada pelos fenômenos jurídicos da justiça e validade.

A “superação histórica do jusnaturalismo e o fracasso político do positivismo abriram caminho para um conjunto amplo e ainda inacabado de reflexões acerca do Direito" 356 . Deste desenvolvimento de correntes jurídicas Pós-Positivistas surge o chamado Neoconstitucionalismo ${ }^{357}$.

Trata-se de teoria que propõe a reaproximação do Direito com a Filosofia, trazendo o centro do ordenamento jurídico, novamente, a questão valorativa, procurando revisitar seu conceito a ponto de evitar as críticas positivistas.

O Neoconstitucionalismo revela-se como "uma tentativa de síntese e superação do jusnaturalismo e do juspositivismo, por meio da relativização do direito escrito que, no caso concreto, pode e deve ser relativizado se não for razoável (e, porque não dizer, justo)". Estes valores morais e

\footnotetext{
${ }^{354}$ LOSANO, Mario G. O pensamento de Norberto Bobbio, do positivismo jurídico à função do direito. in: BOBBIO, Norberto. Da estrutura à função: novos estudos de Teoria do Direito. Barueri, SP: Manole, 2007. prefácio à edição brasileira. pp. 32-33.

${ }^{355}$ BOBBIO, Norberto. Teoria da norma jurídica. Bauru, SP: Edipro, 2008. p. 54.

${ }^{356}$ BARROSO, Luis Roberto. Neoconstitucionalismo e constitucionalização do Direito: o triunfo tardio do Direito Constitucional no Brasil. Disponível em http://www.direitodoestado.com/revista/RERE-9-MAR\%C7O-2007-LUIZ\%20ROBERTO\%20BARROSO.pdf Acessado em: 13.01.2012. ${ }^{357}$ A corrente Neoconstitucionalista foi impulsionada pela produção acadêmica de autores como Robert Alexy e Ronald Dworkin.
} 
éticos estariam dispostos como princípios jurídicos incorporados expressa ou implicitamente às constituições nacionais ${ }^{358}$. Tal como disposto sobre as características juspositivistas, o Neoconstitucionalismo não possui unanimidade sobre sua concepção, porém, alguns de seus contornos desta corrente teórica são ${ }^{359}$ : (i) destaque das normas-princípio no ordenamento jurídico (superando a normas-regra), (ii) método definido pela ponderação como critério de interpretação e aplicação da norma jurídica (em especial diante de situações envolvendo colisão de direitos, (iii) privilegiando a justiça individual (fundada no exame das circunstâncias do caso concreto) em relação à justiça geral (baseada em normas prévias, gerais e abstratas) e (iv) atuação do Poder Judiciário em face da atividade legislativa e executiva, justamente diante da necessidade de maior avaliação de aspectos individuais e concretos, conduzindo à ampliação do ativismo judicial.

Tal como as demais correntes cientificas da Teoria do Direito, também o Neoconstitucionalismo foi, e ainda é, alvo de críticas.

Os questionamentos residem na inexistência de "acordo entre correntes e pensadores com relação à metodologia que deve ser aplicada na tomada de decisões" ${ }^{360}$, o que reflete a falta de critérios decisórios objetivos. O Neoconstitucionalismo acaba por relativizar completamente o próprio conteúdo das normas jurídicas eis que tais normas-princípios contemplariam as mais variadas interpretações e aplicações, o que poderia levar o Direito à vontade e à concepção ética e política de seus aplicadores, notadamente os Juízes.

$\mathrm{Na}$ realidade, o Neoconstitucionalismo padece da mesma dificuldade encontrada pelas demais correntes teóricas, qual seja: o não atendimento à eficácia.

É neste contexto pós-positivista, marcado pela ineficácia do Direito que, em especial nos países dotados de sistemas jurídicos de tradição common law, emerge o chamado Realismo Jurídico. Sua preocupação central estava em dotar "relevo a eficácia, mais do que a justiça ou a validade. Travam uma batalha em duas frentes: contra o jusnaturalismo, que teria uma concepção ideal do direito, e contra o positivismo em sentido estrito, que tem uma concepção formal do direito" "361.

O movimento busca deslocar o eixo até então usual da Teoria do Direto (justiça e validade) para amplificar o papel da eficácia, ou seja, busca avaliar os efeitos práticos produzidos pela norma jurídica.

\footnotetext{
${ }^{358}$ GICO JR., Ivo. Metodologia e Epistemologia da Análise Econômica do Direito. In: Economic Anlysis of Law Review. v. 1, n. 1, jan-jun de 2010. p.13.

359 ÁVILA, Humberto. Neoconstitucionalismo: entre a "Ciência do Direito" e o "Direito da Ciência”; In: Revista Eletrônica de Direito do Estado. Número 17, jan-mar de 2009, Salvador, Bahia.

${ }^{360}$ GICO JR., Ivo. Metodologia e Epistemologia da Análise Econômica do Direito. In: Economic Anlysis of Law Review. v. 1, n. 1, jan-jun de 2010. p. 13.

${ }^{361}$ BOBBIO, Norberto. Teoria da norma jurídica. Bauru, SP: Edipro, 2008. p. 62.
} 
O contexto do Realismo Jurídico faz emergir uma série de outras correntes teóricas do Direito, dentre as quais, aproximadamente em 1930, a chamada Análise Econômica do Direito. A corrente tem como principais referências Ronald Coase, Guido Calabresi e Richard Posner.

Localizando a questão, pertinente esclarecer que o termo Análise Econômica do Direito pode ser empregado numa dupla dimensão: "se refere a métodos da economia para resolver problemas legais e, inversamente, como o direito e as regras legais exercem impacto sobre a economia e seu desenvolvimento" $" 362$.

Assim, a Análise Econômica do Direito pode ser definida como "a aplicação da teoria econômica (seu método) para o exame da formação, estruturação e impacto da aplicação das normas e instituições jurídicas" 363 de modo a retirar " as consequências do fenômeno jurídico da periferia, trazendoas para o centro do debate" ${ }^{364}$.

\section{Elementos da ANÁLISE ECONÔMICA do DIREITO}

Uma das preocupações que ocupa lugar quando dos trabalhos científicos envolvendo a Análise Econômica do Direito reside justamente na melhor contextualização. Ou seja, sua compreensão não significa "que o Direito possa ser reduzido à Economia, e que as categorias jurídicas tradicionais (como direitos subjetivos, deveres jurídicos, culpa, negligência, etc.) possam ser substituídas por categorias econômicas"365, ou seja, dela não podemos compreender um objetivo em reduzir ou submeter o Direito a qualquer espécie de determinismo econômico ${ }^{366}$.

O real sentido da palavra economia, para a compreensão da corrente, reside como "a ciência que estuda o comportamento humano como uma relação entre fins e meios escassos que possuem usos alternativos" "367. Ou seja, "nesse sentido, a abordagem econômica configura, em última análise, um método de pesquisa sobre o comportamento humano diante das diversas instituições que formam a sociedade" 368 .

\footnotetext{
${ }^{362}$ PINHEIRO, Armando C.; SADDI, Jairo. Direito, Economia e Mercados. Rio de Janeiro: Elsevier, 2005. p. 88.

${ }^{363}$ RIBEIRO, Márcia C. P.; et all. Teoroia Geral dos Contratos: contratos empresariais e análise econômica. São Paulo: Campus, 2009.

${ }^{364}$ SALAMA, Bruno M. O que é Direito e Economia. In: TIMM, Luciano. Direito e Economia. Porto Alegre: Livraria do Advogado, 2008. p. 53.

${ }^{365}$ Idem, p. 52

${ }^{366}$ ANDRIGHI, Fátima N. Prefácio. In: TIMM, Luciano. Direito e Economia. Porto Alegre: Livraria do Advogado, 2008.

${ }^{367}$ ROBBINS, Lionel. Na Essay on the Nature and Significance os Economy Science. Londres: Macmilian, 1945, p. 16

${ }^{368}$ PAPP, Leonardo. Análise Econômica do Direito e a (re)inserção da eficácia na Teoria do Direito.
} 
Daí que a economia servirá para a apreciação de questões não necessariamente consideradas "econômicas" ou referentes ao "mercado", já que concebe um conjunto de instrumentos analíticos que permitem a verificação do comportamento humano. Neste sentido, explica Gico: "se envolvem escolhas, então, são condutas passíveis de análise pelo método econômico, pois o objeto da moderna ciência econômica abrange toda forma de comportamento humano que requer a tomada de decisão" ${ }^{369}$.

Sua proximidade em relação ao Direito reside no fato de que "evidentemente, há, no direito, muitas escolhas para analisar: porque é que os legisladores escolhem fazer uma lei com um determinado conteúdo? Porque é que, dado o conteúdo da lei, alguns indivíduos escolhem respeitá-la e outros não? Como é que o sistema judicial toma as decisões relativas à aplicação da lei? Havendo escolhas para analisar, existe a possibilidade de aplicar a Economia"370.

Da localização acima proposta para o método econômico, percebe-se que poderá contribuir quando analise a tendência do comportamento humano diante de determinadas instituições, como o Direito. Mais especificamente, é "a teoria microeconômica [que] oferece uma teoria geral sobre a maneira como as pessoas tomam esse tipo de decisões" 371 .

Esta denominada teoria microeconômica remete, através da leitura acadêmica, à quatro elementos determinantes para a abordagem proposta pela Análise Econômica do Direito.

$\mathrm{O}$ primeiro destes elementos refere-se à chamada escassez. A Análise Econômica do Direito parte do pressuposto de que "os indivíduos vivem em um mundo com recursos escassos" "372, o que torna necessário que as pessoas realizem escolhas.

O segundo elementos chave para a Análise Econômica do Direito é a questão da escolha e da maximização racional. Justamente por constituir um ambiente com recursos escassos, as pessoas agem como maximizadoras racionais de suas satisfações. Trata-se do "traço comum à actuação da generalidade dos seres humanos: a tentativa de ter uma vida tão satisfatória quanto possível, dados os constrangimentos que se debatem. É nisso, afinal, que consiste o pressuposto da escolha racional"373.

In Anais do IV Congresso Anual da Associação Mineira de Direito e Economia.

${ }^{369}$ GICO JR., Ivo. Metodologia e Epistemologia da Análise Econômica do Direito. In: Economic Analysis os Law Review. vol. .1., n.1., jan-jun de 2010. p. 16.

${ }^{370}$ RODRIGUES, Vasco. Análise Econômica do Direito: uma introdução. Coimbra: Gráfica Coimbra, 2007. p. 34.

${ }^{371}$ COOTER, Robert; ULEN, Thomas. Direito e Economia. Porto Alegre: Bookman, 2010. p. 36.

372 SALAMA, Bruno M. O que é Direito e Economia. In: TIMM, Luciano. Direito e Economia. Porto Alegre: Livraria do Advogado, 2008. p. 54.

${ }^{373}$ RODRIGUES, Vasco. Análise Econômica do Direito: uma introdução. Coimbra: Gráfica 
Sobre a questão da maximização, importante o fato de que, diante de um cenário de variáveis, o seu humano tende a optar ou decidir por algo que melhor atende suas pretensões individuais. É da natureza humana, portanto, buscar os melhores benefícios com os menores custos. Esta maximização racional não diz respeito exclusivamente ao critério monetário, mas em razão de qualquer ganho pessoal $1^{374}$, o qual, por ser individual e subjetivo, é "não susceptível de comparações inter-pessoais" $" 375$.

O terceiro elemento seria a questão dos incentivos. Se este método econômico busca avaliar o comportamento humano diante do processo decisório, é evidente que tal comportamento é variável de acordo com estímulos externos (positivos ou negativos) oferecidos pelas instituições. Estes incentivos afetarão diretamente a lógica do custo/benefício, o que poderá levar à uma modificação da escolha quando da maximização racional promovida.

Nesse sentido, "o que verdadeiramente interessa à Economia é perceber quais os incentivos a que as pessoas reagem e como é que lhes reagem: o facto de esses incentivos serem, ou não, monetários é irrelevante" ${ }^{376}$.

Por fim, o quarto elemento seria a questão da eficiência. O termo eficiência tem sido largamente utilizado na academia em vários ramos, inclusive Teoria do Estado $^{377}$. Para a Análise Econômica do Direito, o uso da expressão eficiência deverá estar atrelado, em linhas gerais, à impossibilidade de maximização de benefícios sem o aumento dos custos ${ }^{378}$. Este momento seria o mais eficiente.

Ao trabalhar com a eficiência econômica, surgem outras acepções e teorias fundamentais, das quais cumpre citar o denominado "Ótimo de Pareto", segundo o qual uma relação será eficiente quando não for possível melhorar a situação de um indivíduo sem prejudicar a situação de pelo menos um outro indivíduo, e a teoria de Kaldor-Hicks, "de acordo com a qual um resultado pode ser considerado eficiente, mesmo que algumas pessoas fiquem em situação pior, bastando que aqueles que fiquem em situação melhor possam, em tese, compensar os prejudicados"379.

Coimbra, 2007. p. 34.

${ }^{374}$ A primeira delas para esclarecer que "deve ficar subentendido que tanto as satisfações nãomonetárias quanto as monetárias entram no cálculo individual de maximização" (POSNER, Richard. Problemas de Filosofia do Direito. São Paulo: Martins Fontes, 2007, p. 474).

${ }^{375}$ RODRIGUES, Vasco. Análise Econômica do Direito: uma introdução. Coimbra: Gráfica Coimbra, 2007. p. 14.

${ }^{376}$ Idem, p, 37).

${ }^{377}$ O principio da eficiência foi inserido na CF/88 através da emenda 19/98. Coloca-se como uma das metas da Administração Pública Gerencial.

${ }^{378}$ SALAMA, Bruno M. O que é Direito e Economia. In: TIMM, Luciano. Direito e Economia. Porto Alegre: Livraria do Advogado, 2008. p. 55.

${ }^{379}$ LOPES, Sinome Anacleto. O movimento Direito e Economia. In: Revista de Doutrina da $4^{a}$ Região. n. 40, 28 de fevereiro de 2011. Disponível em: www.bdjur.stj.gov.br. 
Estes elementos propostos como métodos econômicos, quando do contexto da Análise Econômica do Direito, possuem aplicação dinâmica, complexa e interligada, ou seja, isso "significa dizer que os comandos contidos nas normas jurídicas são verdadeiros estímulos, interferindo (seja ampliando, seja reduzindo) o grau de escassez dos recursos disponibilizados às pessoas. Em razão disso, diante das normas jurídicas, as pessoas tendem a se comportar de modo a adotar a escolha que mais se aproxime da eficiência, posto que o comportamento eficiente sob a ótica de determinada pessoa, via de regra, coincide com a alternativa que conduzirá à maximização racional de sua utilidade" 380 . Neste sentido, "podemos dizer que a economia fornece uma teoria comportamental para prever como as pessoas reagem às leis" 381 .

Daí que, retomando aquela teoria tridimensional do Direito, pode-se afirmar que a Análise Econômica do Direito está intimamente relacionada à eficácia. Sua aplicação e abordagem pretende a criação de normas as quais, além de válidas, possuem garantia de observação pela sociedade, sejam eficazes. Esta criação de normas (validade) deverá prestigiar, ainda, uma estruturação que consiga efetivamente influenciar o comportamento (a escolha racional) das pessoas.

A abordagem econômica avalia que, para que uma determinada norma jurídica possa atingir os objetivos de sua criação (espírito da lei), deverá propor algum incentivo (positivo ou negativo) para as pessoas, as quais verifiquem que o atendimento ao comando normativo é medida de maximização de seus ganhos, ou, que o seu não atendimento do comando normativo reduz as utilidades pretendidas pelos seus destinatários.

A compreensão da questão proposta pode levar a crer que a Análise Econômica do Direito teria uma aplicação restrita aos direitos patrimoniais tal como questões relacionadas à responsabilidade civil, adimplemento contratual, falência ou defesa da concorrência, entretanto, existem autores defendem a ideia de que a Análise Econômica do Direito aplicado aos problemas presentes nas mais diversas disciplinas jurídicas, já que " a Economia identifica um tema comum a todos os ramos do Direito: as ações de cada um implicam custos (e benefícios) para os outros" ${ }^{\text {"32 }}$.

O presente artigo, portanto, buscará utilizar a Análise Econômica do Direito como instrumento de percepção do contexto paradoxal verificado entre a atuação dos agentes econômicos em busca de um constante crescimento econômico, em especial as empresas privadas, e o enfrentamento das demandas socioambientais (externalidades amplificadoras dos custos de transação).

\footnotetext{
${ }^{380}$ PAPP, Leonardo. Análise Econômica do Direito e a (re)inserção da eficácia na Teoria do Direito. In Anais do IV Congresso Anual da Associação Mineira de Direito e Economia.

${ }^{381}$ COOTER, Robert; ULEN, Thomas. Direito e Economia. Porto Alegre: Bookman, 2010. p. 25.

${ }^{382}$ RODRIGUES, Vasco. Análise Econômica do Direito: uma introdução. Coimbra: Gráfica Coimbra, 2007. p. 35.
} 


\section{A atividade eCONÔMICA EMPRESARIAl E A QUESTÃo SOCIAMBIENTAL}

A atividade empresarial (pública ou privada), através de suas diretrizes e estruturação, é elemento intimamente relacionado, ou responsável, pelo estímulo e movimentação dos agentes de empreendedorismo além do próprio desenvolvimento socioeconômico regional ou nacional. Diante disto, o Direito Empresarial e Econômico regulamentarão estes comportamentos e o campo de atuação dos agentes econômicos (público ou privados), definindo regras estruturantes institucionais, princípios de interpretação de seus sistemas e proporcionando um verdadeiro ordenamento de micro e macroeconomia, no cerne do qual se desenvolvem as leis empíricas próprias, entendidas como leis do mercado ${ }^{383}$.

A grande questão é que esta atuação dos agentes econômicos ocorre em um contexto não limitado ao critério econômico puro, mas também por valores éticos, sociais e ambientais. A conclusão decorre da própria Constituição Federal do Brasil, quando em seu artigo 219 prediz que: “O mercado interno integra o patrimônio nacional e será incentivado de modo a viabilizar o desenvolvimento cultural e sócio-econômico, o bem-estar da população e a autonomia tecnológica do País, nos termos de lei federal". Derani ressalta , ainda, o artigo 170 da Constituição, o qual determina uma ordem econômica com a finalidade de assegurar a todos existência digna, conforme os ditames da justiça social" 384 .

A questão encontra interpretação realizada pelo Ministro Celso de Mello na ADI 3.540 a qual, embora se refira ao meio ambiente no foco da decisão, traz ao centro o valor social, representado tanto por meio das próprias modalidades de meio ambiente quanto, em especial, no tocante à tutela da saúde, segurança, cultura, trabalho e bem estar da população:

A atividade econômica não pode ser exercida em desarmonia com os princípios destinados a tornar efetiva a proteção ao meio ambiente. A incolumidade do meio ambiente não pode ser comprometida por interesses empresariais nem ficar dependente de motivações de índole meramente econômica, ainda mais se se tiver presente que a atividade econômica, considerada a disciplina constitucional que a rege, está subordinada, dentre outros princípios gerais, àquele que privilegia a

\footnotetext{
${ }^{383}$ VENTURI. Eliseu Raphael; KOLADICZ Aline. Eficiência Econômica e Desenvolvimento Integral: Economia e Direito Cerrados à Consecução Constitucional. Disponível em http://www.ambitojuridico.com.br/site/index.php?n_link=revista_artigos_leitura\&artigo_id=9484. Acessado em 10.07.2012.

${ }^{384}$ DERANI, C. Direito ambiental econômico. São Paulo: Saraiva, 2008. p. 236.
} 
'defesa do meio ambiente' (CF, art. 170, VI), que traduz conceito amplo e abrangente das noções de meio ambiente natural, de meio ambiente cultural, de meio ambiente artificial (espaço urbano) e de meio ambiente laboral. Doutrina. Os instrumentos jurídicos de caráter legal e de natureza constitucional objetivam viabilizar a tutela efetiva do meio ambiente, para que não se alterem as propriedades e os atributos que the são inerentes, o que provocaria inaceitável comprometimento da saúde, segurança, cultura, trabalho e bem-estar da população, além de causar graves danos ecológicos ao patrimônio ambiental, considerado este em seu aspecto físico ou natural. (ADI 3.540-MC, Rel. Min. Celso de Mello, julgamento em 1-9-05, DJ de 3-2-06).

Desta reflexão entre as esferas social e ambiental é que o presente artigo extrai o que passará a designar por "questão socioambiental". O preceito preconizado pela norma constitucional refletirá na necessidade de assimilação de uma responsabilidade empresarial que passará a considerar os critérios socioambientais (responsabilidade socioambiental corporativa). De modo prático, objetiva-se a analisar a atuação empresarial, eminentemente econômica na alocação dos recursos, e discutir se tal atividade pode (ou deve) contribuir para o desenvolvimento sustentável a partir de uma gestão socialmente compromissada em desempenhar papel fundamental para a valorização do aspecto socioambiental.

A situação conflituosa verificada deve ser apreciada sob a lógica e Teoria do Direito, sendo certo que o conflito aparente poderá encontrar diferentes respostas a partir das variações teóricas aplicadas. A tentativa de analisar a questão sob o viés da metodologia econômica pretende conceber uma possibilidade de vinculação dos conceitos de eficiência econômica ao de desenvolvimento sustentável.

A ordem jurídica brasileira trata com esta questão junto ao artigo 225 da Constituição, ao determinar estrita observância ao desenvolvimento sustentável, consubstanciado num acesso equitativo aos recursos naturais, para a presente e futura geração ${ }^{385}$. Sachs trabalha com o conceito de desenvolvimento

\footnotetext{
${ }^{385}$ Estes princípios já foram apresentados pelo relatório da CMAD: "Desenvolvimento sustentável pode ser entendido como a forma de desenvolvimento que satisfaz as necessidades das gerações presentes sem comprometer a capacidade das gerações futuras de alcançar a satisfação de seus próprios interesses. Essa idéia contém dois conceitos-chave: a) $\mathrm{O}$ conceito de necessidade, em particular as necessidades essenciais dos países pobres, paras as quais deve ser dada prioridade absoluta; b) A idéia da existência de limitações à capacidade do meio ambiente de satisfazer as necessidades atuais e futuras impostas pelo estágio atual da tecnologia e da organização social". THE WORLD Comission on Environment and Development. Our commom future. p. 59. apud Carneiro, Ricardo. Direito Ambiental. Uma Abordagem Econômica. Rio de Janeiro: Forense, 2001. p. 54.
} 
sustentável através do atendimento de três pilares fundamentais: relevância social, prudência ecológica e viabilidade econômica ${ }^{386}$.

\section{A análise econômica da QUestão SOCIOAMBIENTAL}

Da apresentação das teorias do Direito, chegou-se à proposta da Análise Econômica, a qual, conforme já apresentado, possui determinados elementos formadores caracterizados pela maximização dos resultados, escassez dos recursos, incentivos ou estímulos e a eficiência econômica. A apreciação do paradoxo existente entre a atividade empresarial e o atendimento às demandas socioambientais registrará um primeiro obstáculo verificado na questão da maximização de resultados (ganhos).

A maximização dos resultados decorre da própria eficiência econômica, se visto apenas sob o aspecto do ganho de resultados. Ou seja, a concepção pura econômica traduz a ideia de uma proposta básica da alocação de recursos no desenvolvimento de uma atividade produtiva. Esta atividade tende a verificar os recursos naturais como mera matéria-prima e toda a cadeia humana como elemento para atingimento do "fim negocial"387.

Desta forma, questões não econômicas seriam verificadas como ampliação de custos de transação, dos quais estes agentes preferem afastar-se, eis que externalidades negativas ${ }^{388}$. Este seria um primeiro risco.

O conflito parece estar alocado, ainda, em outro elemento típico da Análise Econômica do Direito, a questão da escassez! Milaré insiste na sustentabilidade como atributo necessário a ser respeitado no tratamento dos recursos ambientais, em especial dos recursos naturais ${ }^{389}$. Isto porque é fato que o meio ambiente natural não pode sucumbir ou ser exterminado sob o pretexto de crescimento ou desenvolvimento puramente econômico. Segundo Fiorillo:

\footnotetext{
${ }^{386}$ SACHS, Ignacy. Caminhos para o desenvolvimento sustentável. 4. ed. Rio de Janeiro: Garamond, 2002. p. 35.

387 "uma forma de racionalidade imperfeita que assume que as pessoas buscam maximizar sua utilidade, mas estão sujeitas a restrições cognitivas [...]", de modo que, apesar de a intenção do agente econômico "[...] continuar sendo maximizar sua utilidade, ele somente poderá fazê-lo dentro dos limites impostos pela capacidade de absorver e processar tais informações" (PINHEIRO, Armando C.; SADDI, Jairo. Direito, Economia e Mercados. Rio de Janeiro: Elsevier, 2005, p. 65).

${ }^{388} \mathrm{O}$ conceito de externalidade foi desenvolvido pelo economista Pigou, na década de 1920, o qual estabeleceu: "existe uma externalidade quando a produção de uma empresa (ou um consumo individual) afeta o processo produtivo ou um padrão de vida de outras empresas ou pessoas, na ausência de uma transação comercial entre elas" (MOURA, Luiz Antônio Abdalla. Economia ambiental: gestão de custos e investimentos. p. 5. Para o Autor, ainda, a externalidade "refere-se à ação que um determinado sistema de produção causa em outros sistemas externos".

${ }^{389}$ MILARÉ, Edis. Direito do Meio Ambiente: doutrina, jurisprudência, glossário. 5. ed. São Paulo: Revista dos Tribunais, 2007. p. 68.
} 
[...] constata-se que os recursos ambientais não são inesgotáveis, tornando-se inadmissível que as atividades econômicas desenvolvam-se alheias a esse fato. Busca-se com isso a coexistência harmônica entre economia e meio ambiente. Permite-se o desenvolvimento, mas de forma sustentável, planejada, para que os recursos hoje existentes não se esgotem ou tornem-se inócuos ${ }^{390}$.

No mesmo sentido, sobre o aparente conflito entre crescimento econômico e sustentabilidade socioambiental, Derani reflete a passagem histórica quando a Revolução Industrial tinha a subserviência do meio ambiente:

[...] o início do desenvolvimento da produção industrial estava atrelado ao fato da existência de recursos adequados. Aço, carvão, ferro, alimento representaram condições decisivas para a Revolução Industrial, apesar da não-monetarização do valor da existência de tais recursos. Cidades cresceram e minguaram a medida que os recursos naturais que sustentavam o seu desenvolvimento desapareciam ${ }^{391}$.

O conflito, entretanto, permite maiores reflexões, de forma a minimizá-lo.

Dentre as características ou elementos propostos para a Análise Econômica do Direito, foi registrada a questão da eficiência, ou seja, se de um lado aparece uma tendência pura econômica que tende a ampliar (ou maximizar) as ganhos individuais, por outro, deve-se considerar que a eficiência (registrese a existência de uma pluralidade de teorias acerca da eficiência econômica), apura a questão de maximização de resultados com a diminuição dos custos.

É justamente no aspecto da redução ou inexistência de custos que se insere a questão socioambiental. Isso por que é essencial "manutenção das qualidades que satisfaçam as normas técnicas"392. Dentro desta interpretação, pode-se compreender que a eficiência econômica não pode ser buscada a despeito dos padrões de qualidade (muitos dos quais fornecidos pelas normas e certificações ${ }^{393}$ de padrões de gestão adequada à responsabilidade socioambiental).

A eficiência, portanto, terá como suporte a maximização de resultados dentro da limitação do uso de seus recursos escassos. A "propriedade de alocação de um recurso em maximizar o excedente total recebido por todos

\footnotetext{
${ }^{390}$ FIORILLO, C. A. P. Curso de direito ambiental brasileiro. São Paulo: Saraiva, 2005, p. 29.

${ }^{391}$ DERANI, C. Direito ambiental econômico. São Paulo: Saraiva, 2008. p. 100.

${ }^{392}$ FRANÇA, Phillip Gil. Breves reflexões sobre o Direito, a Economia e a atividade regulatória do Estado. Revista Zênite de Direito Administrativo e LRF, Curitiba, ano IV, n. 71, p. 998, jun. 2007. p. 198. ${ }^{393}$ LOUETTE, Anne (Org). Compêndio para a sustentabilidade. Ferramentas de gestão de responsabilidade socioambiental. São Paulo: Willis Harman House e AntaKarana, 2007. pp. 138 - 175.
} 
os membros da sociedade" 394 . Mankiw considera o campo do bem-estar e conceitua a eqüidade como a "justa distribuição de prosperidade econômica entre os membros da sociedade", por meio de distribuição imparcial de bemestar entre os integrantes desta mesma sociedade.

Esta ótica, que parte do pressuposto da escassez, tal como ocorreu na proposição do problema econômico, tem como objetivo central alcançar a maior eficiência possível nas alocações materiais e sociais, em especial através da maximização das utilidades individuais (Pareto) e da maximização da riqueza social ${ }^{395}$.

A eficiência econômica é obtida ou verificada através da aplicação do critério de Pareto (também chamada 'otimalidade de Pareto'). Segundo este critério, uma distribuição de recursos é eficiente se for impossível aumentar a utilidade de uma pessoa sem reduzir a utilidade de alguma outra pessoa. Nesta última assertiva, a expressão utilidade pode ser tomada no sentido de bem-estar ${ }^{396 .}$

Se concebêssemos a questão do ótimo de Pareto, pura e simplesmente, através de uma supremacia do critério econômico sobre os demais, realmente não parece possível resolver o paradoxo por este viés. Porém, deve-se compreender que este critério econômico não se isola, tampouco se sobreposiciona sob os preceitos sociais e ambientais. Isso decorre da própria interpretação integral do conteúdo constitucional. Ou seja, o modelo constitucional, por si mesmo, já apresenta determinados limites ou barreiras ao capitalismo puro, tal como limitações à iniciativa privada, livre concorrência e propriedade.

Daí a chamada economia do bem-estar que busca o equilíbrio entre os agente econômicos (titulares das atividades econômicas) e demais atores do cenário social, tais como trabalhadores, consumidores e até mesmo o próprio meio ambiente.

Amartya Sen aborda a questão ao considerar que um determinado Estado Social atingiu o seu ótimo de Pareto, quando for absolutamente impossível aumentar a utilidade de uma pessoa, sem contudo reduzir a utilidade de outra pessoa. $\mathrm{O}$ autor entende a eficácia em conjunto com a concepção de utilitarismo $\mathrm{m}^{397}$.

\footnotetext{
394 MANKIW, N. Gregory. Introdução à economia: princípios de micro e macroeconomia. Tradução de Maria José Cyhlar Monteiro. Rio de Janeiro: Campus, 2001. pp. 5, 153, 801.

${ }^{395}$ GALDINO, Flavio. Introdução à Teoria dos Custos dos Direitos: direitos não nascem em árvores. Rio de Janeiro: Lúmen Júris, 2005. p. 242.

${ }^{396}$ Idem, p. 242-243.

397 SEN, Amartya Kumar. Sobre Ética e Economia. Trad. Laura Teixeira Motta. São Paulo: Companhia das Letras, 1999. pp. 47-48.
} 
Desta forma, a eficiência, de acordo com a interpretação do texto constitucional, sendo concebida através do chamado ótimo de Pareto, aproxima-se definitivamente do chamado desenvolvimento sustentável. Neste sentido Derani:

[...] a economia de mercado atinge seu grau ótimo quando realiza uma satisfatória relação entre o uso de um recurso natural e sua conservação, encontrando um preço que permite a utilização do bem ao mesmo tempo que conserva. Em outras palavras, a relação uso e não uso deve atingir um estágio ótimo que permita a continuação desta prática econômica, ou seja, a sustentabilidade do desenvolvimento ${ }^{398}$.

Por fim, cabe discorrer acerca da questão dos incentivos, como elemento da Análise Econômica do Direito. É justamente na compreensão dos incentivos que propõe-se uma perspectiva positiva ao paradoxo proposto neste artigo.

Da compreensão dos fundamentos da República Federativa do Brasil, conforme se extrai de seu preâmbulo, está o desenvolvimento. O desenvolvimento, através da interpretação da lógica constitucional, decorre, em especial, através de duas principais frentes de atuação do Estado: (i) através da redução de desigualdades sociais e regionais, da erradicação da pobreza e a marginalização e a firmar a cidadania e a dignidade da pessoa humana, e (ii) o controle do sistema financeiro nacional por meio de atividade regulatória.

A evolução do método proposto para aferição do grau de desenvolvimento demonstra esta compreensão de escopo deste fundamento. Desta forma, enquanto por muito tempo prestigiou-se crescimento com base no Produto Interno Bruto - PIB, pelo meio do qual se considera apenas a dimensão econômica, inicia-se a difusão do critério denominado Índice de Desenvolvimento Humano - IDH, que incorpora, além do crescimento, fatores sociais como escolaridade e a longevidade ${ }^{399}$.

Ou seja, o desenvolvimento econômico há de abarcar consigo mutações de ordem social e política, possibilitando efetivar objetivos constitucionais. O desenvolvimento deve ser a causa das transformações em um espaço democrático. Conforme Sen:

Se o desenvolvimento econômico não trouxer consigo modificações de caráter social e político, de modo a efetivar os objetivos constitucionais, e se o desenvolvimento social e político não for a um tempo o resultado e a causa de transformações econômicas, sob o manto democrático, será

\footnotetext{
${ }^{398}$ DERANI, C. Direito ambiental econômico. São Paulo: Saraiva, 2008. p. 115.

${ }^{399}$ SEN, Amartya Kumar. O Desenvolvimento Humano e IDH. Disponível em: http://www.pnud. org.br/idh/. Acesso em: 29 fev. 2008.
} 
porque, de fato, não se teve desenvolvimento. As modificações verificadas em um desses setores terão sido tão superficiais, tão epidérmicas, que não deixam traços ${ }^{400}$.

No mesmo sentido, Bresser Pereira entende que o desenvolvimento:

Será sempre, porém, um sistema social. Suas partes, portanto, serão interdependentes. Quando houver modificações reais na estrutura econômica, estas repercutirão nas estruturas política e social e vice-versa. Se a repercussão for pequena, se o crescimento da renda, por exemplo, não for acompanhado de transformações políticas e sociais, isto será sinal de que aquele crescimento da renda não foi significativo para o desenvolvimento, não podendo ser considerado como tal"401.

Destas finalidades do Estado que tornam fundamental a contemplação das questões sociais ao contexto de desenvolvimento, pode-se compreender que na finalidade regulatória econômica também decorrerá o dever de incentivar um cenário de sustentabilidade socioambiental.

O incentivo, ou estímulo, em conjunto com os valores já discorridos (como uma relativização da eficiência pura econômica), permitem imaginar que um instrumental hábil a harmonizar este paradoxo seria a própria regulação incentivada.

Neste contexto destacam-se as ferramentas de gestão de responsabilidade socioambiental e os indicadores de sustentabilidade ${ }^{402}$ as quais "possibilitam estabelecer uma cultura, bem como uma consciência organizacionais que insculpem valores internos e traçam procedimentos de prevenção de danos ao ambiente e aos consumidores, agindo assim o responsável pelo negócio em conformidade às Leis ambientais, à Constituição e aos tratados internacionais, pela via da livre aderência e progressiva qualificação do agente econômico" ${ }^{403}$.

É evidente que uma das barreiras do investimento sobre as questões socioambientais no meio empresarial está localizado na questão da maximização dos seus resultados (ganhos).

Desta forma, a partir do momento que este corpo empresarial passa a investir numa estruturação voltada ao aspecto socioambiental, parece que serão

\footnotetext{
${ }^{400}$ BRESSER-PEREIRA, Luiz Carlos. Desenvolvimento e crise no Brasil: história, economia e política de Getúlio Vargas a Lula. São Paulo: Editora 34, 2003. pp. 31-32.

${ }^{401}$ Idem. Op. cit. p. 31-32.

${ }^{402}$ Neste sentido vale verificar a obra de LOUETTE, Anne (Org). Compêndio para a sustentabilidade. Ferramentas de gestão de responsabilidade socioambiental. São Paulo: Willis Harman House e AntaKarana, 2007 e BELLEN, H. M. V. Indicadores de sustentabilidade: uma análise comparativa. Rio de Janeiro: Editora FGV, 2005.

${ }^{403}$ PINHEIRO, Armando C.; SADDI, Jairo. Direito, Economia e Mercados. Rio de Janeiro: Elsevier, 2005.
} 
ampliados os seus custos de transação. Este aumento do custo de transação, não será bem visto pelos investidores desta empresa, os quais esperam apenas e tão somente a maximização de seus resultados.

Neste contexto, em que a viabilidade econômica por vezes assume importância vital em detrimento da ambiental, as organizações brasileiras vêm implementando ações no sentido de incorporar os conceitos de desenvolvimento sustentável. É importante ressaltar que a longo prazo a procura por inovações para atender a padrões ambientais e a busca de materiais alternativos podem determinar redução dos custos ${ }^{404}$.

Diante deste quadro, parece que recai sobre a regulação a função de promover incentivos positivos no intuito de fomentar tal prática empresarial.

Outro fator fundamental, será o de conceber a própria força do mercado. É fato que o mercado ditará o sucesso de determinado agente econômico. O mencionado sucesso está intimamente vinculado ao mercado consumidor, logo, é deste segmento a escolha sobre quais práticas empresariais poderão ser prestigiadas. Aqui parece que a conscientização do consumidor assume papel fundamental.

No mercado financeiro internacional e nacional, investidores têm privilegiado empresas socialmente responsáveis, sustentáveis e rentáveis para investir seus recursos. Esses tipos de investimentos denominados "investimentos socialmente responsáveis" (SRI) consideram que empresas sustentáveis geram valor para o acionista a longo prazo, pois se apresentam mais preparadas para enfrentar riscos econômicos, sociais e ambientais (Bovespa, 2006)" 405 .

Em território nacional cabe citar o chamado Índice de Sustentabilidade Empresarial, o ISE, criado pela BOVESPA para fornecer aos investidores uma opção em formação de carteira de ações a partir de empresas com reconhecidas práticas de responsabilidade socioambientais ${ }^{406}$. Sobre o índice, pairam as

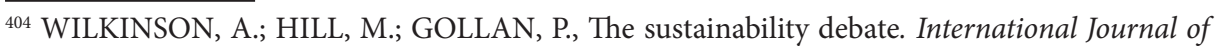
Operations \& Production Management, London, v. 21, n.12, pp. 14921500, 2001.

${ }^{405}$ QUELHAS. Osvaldo Luiz Gonçalves; SILVA AGUIAR, Lilian Simone. Sustentabilidade Empresarial e o Impacto no Custo de Capital Próprio das Empresas de Capital Aberto. Universidade Federal Fluminense - UFF, Rio de Janeiro, 2006.

406 "Iniciativa pioneira na América Latina, o Índice de Sustentabilidade Empresarial (ISE) busca criar um ambiente de investimento compatível com as demandas de desenvolvimento sustentável da sociedade contemporânea e estimular a responsabilidade ética das corporações. Iniciado em 2005, foi originalmente financiado pela International Finance Corporation (IFC), braço financei- 
dúvidas se a assunção de práticas de gestão socioambientais retrata um custo extra de transação (custo de capital), ou refletem resultados positivos em favor dos investidores. Ao analisar especificamente o ISE, Quelhas e Aguiar da Silva levantam que:

A participação no Índice de Sustentabilidade da Bovespa, o ISE, foi determinada como padrão de excelência em sustentabilidade. Os resultados do modelo, testado para empresas brasileiras do $\mathrm{IBrX}$ em dois períodos (2000 a 2002 e 2003 a 2005), confirmaram que ao adotarem as práticas de sustentabilidade existe uma redução do risco sistemático, embora seja estatisticamente significante somente no primeiro período analisado.

Este resultado, ainda não abordado na literatura, confirma a expectativa de que, ao aderir aos padrões de sustentabilidade, a empresa reduz o risco corporativo medido pelo risco sistemático, determinando assim a redução do custo de capital próprio, aumentando o valor econômico da empresa.

Diante destas considerações, ainda que a escassez de recursos e a maximização dos ganhos sejam questões que, a priori, possam criar barreiras sobre a necessária responsabilidade socioambiental junto aos agentes econômicos, é fato que a eficiência guarda intima relação com o chamado desenvolvimento sustentável. No mesmo contexto, fundamental a criação de incentivos orientem as forças de mercado, seja por estabelecimento estatal, seja por posicionamento do mercado consumidor (valoração àquelas empresas que atendem os preceitos de sustentabilidade).

ro do Banco Mundial, e seu desenho metodológico é responsabilidade do Centro de Estudos em Sustentabilidade (GVCes) da Escola de Administração de Empresas de São Paulo da Fundação Getúlio Vargas (FGV-EAESP). O ISE é uma ferramenta para análise comparativa da performance das empresas listadas na BM\&FBOVESPA sob o aspecto da sustentabilidade corporativa, baseada em eficiência econômica, equilíbrio ambiental, justiça social e governança corporativa. Também amplia o entendimento sobre empresas e grupos comprometidos com a sustentabilidade, diferenciando-os em termos de qualidade, nível de compromisso com o desenvolvimento sustentável, equidade, transparência e prestação de contas, natureza do produto, além do desempenho empresarial nas dimensões econômico-financeira, social, ambiental e de mudanças climáticas". Extraído do site oficial BM\&V e BOVESPA. Disponível em: http://www.bmfbovespa.com.br/indices/ResumoIndice.aspx? Indice=ISE\&idioma=pt-br. Acessado em 15.07.2012. 


\section{Conclusão}

Da compreensão das questões acima propostas, pode-se extrair que a Análise Econômica do Direito, se ferramenta concebida exclusivamente para uma interpretação de viés econômico puro, estará limitada na sua capacidade de responder as atuais demandas socioambientais.

Por outro lado, a sua compreensão como método que permite a contemplação de critérios não econômicos, poderá caminhar à elaboração de perspectivas de resposta ao paradoxo da modernidade (crescimento econômico X demanda socioambiental).

A primeira perspectiva conclusiva refere-se a absorção de que o mercado e a atividade mercantil refletem uma prática social, e não individualista, e desta forma, deverá estar dotada de estrutura, organização e agentes comprometidos com critérios éticos a serem projetados sobre todas as esferas de suas relações, sejam privadas ou públicas ${ }^{407}$.

Outra percepção é de que estas práticas sociais de forma alguma poderão estar dissociadas do sistema integral constitucional, do qual decorre a necessidade de um desenvolvimento sustentável. Leff reflete que "o discurso da sustentabilidade chegou a afirmar o propósito e a possibilidade de conseguir um crescimento econômico sustentável através dos mecanismos de mercado, sem justificar sua capacidade de internalizar as condições de sustentabilidade ecológica". Prossegue o autor no sentido de que o crescimento econômico orientando por um livre mercado, alcançará seu propósito sem refletir "a capacidade do mercado de dar o justo valor à natureza e à cultura; de internalizar as externalidades ambientais e dissolver as desigualdades sociais; de reverter as leis da entropia e atualizar as preferências das futuras gerações"408.

Uma terceira perspectiva reside no fato de que a eficiência econômica deverá ser interpretada sobre um aspecto mais amplo. Um redimensionamento capaz de incorporar os preceitos socioambientais. Desta forma, a noção "eficiência econômica" seria justamente aquela que atende aos preceitos socioambientais. O ótimo de Pareto refletiria a eficiência, consubstanciada no equilíbrio do desenvolvimento sustentável.

Daqui surge uma quarta perspectiva proposta, a de atendimento de um desenvolvimento sustentável, a partir de incentivos aos agentes de mercado (Estado, investidores ou consumidores).

Neste sentido, Sachs lembra que a história mostra que o desenvolvimento sustentável é inviável sem restrições das forças do mercado. O autor registra que

\footnotetext{
407 SOLOMON, Robert. Business ethics. A Companion to Ethics. SINGER, Peter (Org.). Malden:Blackwell, 1995. pp. 354-365.

${ }^{408}$ LEFF, Enrique. Saber Ambiental: sustentabilidade, racionalidade, complexidade, poder. Rio de Janeiro: Vozes, 2001. pp. 20 - 24.
} 
subsídios bem dimensionados podem ter um importante papel na promoção de padrões de aproveitamento de recursos sustentáveis ${ }^{409}$. Acima foi apresentada a questão do Índice de Sustentabilidade Empresarial (como iniciativa privada), mas a própria "tributação verde" e as práticas de fomento estatal ratificam este entendimento.

${ }^{409}$ SACHS, Ignacy. Caminhos para o desenvolvimento sustentável. 4. ed. Rio de Janeiro: Garamond, 2002. p.56. 


\section{REFERENCIAS}

ANDRIGHI, Fátima N. Prefácio. In: TIMM, Luciano. Direito e Economia. Porto Alegre: Livraria do Advogado, 2008.

ÁVILA, Humberto. Neoconstitucionalismo: entre a "Ciência do Direito" e o "Direito da Ciência". Revista Eletrônica de Direito do Estado. n. 17, jan-mar de 2009, Salvador, Bahia.

BARROSO, Luis Roberto. Neoconstitucionalismo e constitucionalização do Direito: o triunfo tardio do Direito Constitucional no Brasil. Disponível em http://www.direitodoestado.com/revista/RERE-9-MAR\%C7O-2007LUIZ\%20ROBERTO\%20BARROSO.pdf. Acessado em 13.01.2012.

BOBBIO, Norberto. Teoria da norma jurídica. Bauru, São Paulo: Edipro, 2008.

BELLEN, H. M. V. Indicadores de sustentabilidade: uma análise comparativa. Rio de Janeiro: FGV, 2005.

BRESSER-PEREIRA, Luiz Carlos. Desenvolvimento e Crise no Brasil: história, economia e política de Getúlio Vargas a Lula. São Paulo, 2003.

COOTER, Robert; ULEN, Thomas. Direito e Economia. Porto Alegre: Bookman, 2010.

DERANI, Cristiane. Direito Ambiental Econômico. 3. ed. São Paulo: Saraiva, 2008.

FIORILlo, Celso Antônio Pacheco. Curso de Direito Ambiental Brasileiro. São Paulo: Saraiva, 2005.

FRANÇA, Phillip Gil. Breves Reflexões sobre o Direito, a Economia e a Atividade Regulatória do Estado. Revista Zênite de Direito Administrativo e LRF, Curitiba, ano IV, n. 71, jun. 2007.

GALDINO, Flavio. Introdução à Teoria dos Custos dos Direitos: direitos não nascem em árvores. Rio de Janeiro: Lúmen Júris, 2005.

GICO JR., Ivo. Metodologia e Epistemologia da Análise Econômica do Direito. In: Economic Anlysis of Law Review. vol. 1, n. 1, jan-jun de 2010. 
GUIMARÃES, José de Miranda. Direito Natural: visão metafisica $e$ antropológica. Rio de Janeiro: Forense Universitária, 1991.

LEFF, Enrique. Saber Ambiental: sustentabilidade, racionalidade, complexidade, poder. Rio de Janeiro: Vozes, 2001.

LOPES, Sinome Anacleto. O movimento Direito e Economia. In: Revista de Doutrina da $4^{\mathrm{a}}$ Região. n. 40, 28 de fevereiro de 2011. Disponível em: www. bdjur.stj.gov.br.

LOSANO, Mario G. O pensamento de Norberto Bobbio, do positivismo jurídico à função do direito. In: BOBBIO, Norberto. Da estrutura à função: novos estudos de Teoria do Direito. Barueri, SP: Manole, 2007.

LOUETTE, Anne (Org). Compêndio para a Sustentabilidade. Ferramentas de gestão de responsabilidade socioambiental. São Paulo: Willis Harman House e Anta Karana, 2007.

MANKIW, N. Gregory. Introdução à Economia: princípios de micro e macroeconomia. Tradução de Maria José Cyhlar Monteiro. Rio de Janeiro: Campus, 2001.

MILARÉ, Edis. Direito do Meio Ambiente: doutrina, jurisprudência, glossário. 5. ed. São Paulo: Revista dos Tribunais, 2007.

MOURA, Luiz Antônio Abdalla. Economia Ambiental: gestão de custos e investimentos. São Paulo: Juarez de Oliveira, 2000.

PAPP, Leonardo. Análise Econômica do Direito e a (re)inserção da eficácia na Teoria do Direito. In Anais do IV Congresso Anual da Associação Mineira de Direito e Economia.

PINHEIRO, Armando Castelar; SADDI, Jairo. Direito, Economia e Mercados. Rio de Janeiro: Elsevier, 2005.

POSNER, Richard. Problemas de Filosofia do Direito. São Paulo: Martins Fontes, 2007.

QUELHAS. Osvaldo Luiz Gonçalves; SILVA AGUIAR, Lilian Simone. Sustentabilidade Empresarial e o Impacto no Custo de Capital Próprio das 
Empresas de Capital Aberto. Universidade Federal Fluminense - UFF, Rio de Janeiro, 2006.

RADBRUCH, Gustav. Filosofia do Direito. Coimbra: Coimbra Editora, 1997.

REALE, Miguel. Filosofia do Direito. São Paulo: Saraiva, 2010.

RIBEIRO, Márcia Carla. Teoroia Geral dos Contratos: contratos empresariais e análise econômica. São Paulo: Campus, 2009.

ROBBINS, Lionel. Na Essay on the Nature and Significance os Economy Science. Londres: Macmilian, 1945.

RODRIGUES, Vasco. Análise Econômica do Direito: uma introdução. Coimbra: Gráfica Coimbra, 2007.

SACHS, Ignacy. Caminhos para o Desenvolvimento Sustentável. 4. ed. Rio de Janeiro: Garamond, 2002.

SALAMA, Bruno M. O que é Direito e Economia. In: TIMM, Luciano. Direito e Economia. Porto Alegre: Livraria do Advogado, 2008.

SEN, Amartya Kumar. Sobre Ética e Economia. Trad. Laura Teixeira Motta. São Paulo: Companhia das Letras, 1999.

SOLOMON, Robert. Business ethics. A Companion to Ethics. SINGER, Peter (Org.). Malden:Blackwell, 1995.

SEN, Amartya Kumar. O Desenvolvimento Humano e IDH. Disponível em: http://www.pnud.org.br/idh/. Acesadso em: 29.02.2008.

STIGLER. Georde. Law or Economics? The Journal of Law and Economics, v. 35, n. 2, out. 1992.

VENTURI. Eliseu Raphael; KOLADICZ Aline. Eficiência Econômica e Desenvolvimento Integral: Economia e Direito Cerrados à Consecução Constitucional. Disponível em: http://www.ambito-juridico.com.br/site/ index.php?n_link=revista_artigos_leitura\&artigo_id=9484. Acessado em: 10.06.2012. 
WILKINSON, A.; HILL, M.; GOLLAN, P., The Sustainability Debate. International Journal of Operations \& Production Management, London, vol. 21, n.12.

The World Comission on Environment and Development. Our commom future. apud Carneiro, Ricardo. Direito Ambiental. Uma Abordagem Econômica. Rio de Janeiro: Forense, 2001. 